\title{
RPLP1 promotes tumor metastasis and is associated with a poor prognosis in triple-negative breast cancer patients
}

\author{
Zhixian $\mathrm{He}^{1,2+}$, Qian Xu ${ }^{2 \dagger}$, Xi Wang ${ }^{2+}$, Jun Wang ${ }^{2}$, Xiangming $\mathrm{Mu}^{3}$, Yunhui Cai ${ }^{3}$, Yangyang Qian ${ }^{3}$, Weiwei Shao ${ }^{3 *}$
} and Zhimin Shao ${ }^{1 *}$

\begin{abstract}
Background: Cancer metastasis is the major reason for cancer related deaths, and the mechanism of cancer metastasis still unclear. RPLP1, a member of a group of proteins known as ribosomal proteins, is associated with tumorigenesis and primary cell immortalization and is involved in cellular transformation. However, the expression and potential function of RPLP1 in TNBC remain unclear.

Methods: The expression of RPLP1 in TNBC tissues and cell lines were detected with Real-Time PCR and western blotting. 81 cases of TNBC tissue samples and adjacent non-tumor tissue samples were tested by immunochemistry to determine the correlation between the RPLP1 expression and clinicopathological characteristics. In vitro, we determined the role and mechanistic pathways of RPLP1 in tumor metastasis in TNBC cell lines.

Results: In this study, we detected high levels of RPLP1 expression in TNBC samples and cell lines. RPLP1 is upregulated in triple-negative breast cancer (TNBC) tissues and cells, and high expression levels correlate with an increased risk of recurrence and metastasis. Furthermore, high RPLP1 expression was associated with a poor prognosis and was an independent prognostic marker for TNBC. In RPLP1-induced cancer metastasis, RPLP1 may increase cancer cell invasion, which is likely the result of its effect on the cancer cell epithelial-mesenchymal transition.
\end{abstract}

Conclusions: Altogether, our findings indicate RPLP1 is a poor prognostic potential biomarker and anti-metastasis candidate therapeutic target in triple-negative breast cancer.

Keywords: RPLP1, Triple-negative breast cancer, Epithelial-mesenchymal transition

\section{Background}

Breast cancer is the most common cancer, and is a leading cause of death among females [1-3]. Triple-negative breast cancer (TNBC), which is defined by a lack of the estrogen receptor (ER), progesterone receptor (PR), and the human epidermal growth factor receptor 2 (HER2) receptor, is resistant to conventional hormone and

\footnotetext{
*Correspondence: runningbichon@126.com; shaozhiminfd@163.com

${ }^{\dagger}$ Zhixian He, Qian Xu and Xi Wang contributed equally to this work

${ }^{1}$ Department of Breast Surgery, Shanghai Cancer Center, Fudan

University, Shanghai 200032, People's Republic of China

${ }^{3}$ Department of General Surgery, The Fourth Affiliated Hospital

of Nantong University, Yancheng 224000, Jiangsu, People's Republic

of China

Full list of author information is available at the end of the article
}

anti-HER2-targeted therapies $[4,5]$. Therefore, TNBC has a higher recurrence and mortality rate compared to other breast cancer subtypes [6]. Thus, investigating the mechanism of cancer development in TNBC tumors will likely be highly beneficial in monitoring tumor progression and enhancing the overall prognosis [7].

Ribosomes, the organelles that catalyze protein synthesis, consist of a small $40 \mathrm{~S}$ subunit and a large $60 \mathrm{~S}$ subunit [8]. Together these subunits are composed of four RNA species and approximately 80 structurally distinct ribosomal proteins [9]. In eukaryotes, the ribosomal stalk complex is comprised of a RP Large P0 (P0) subunit and two heterodimers of RP Large P1 (RPLP1) and RP Large P2 (RPLP2) [10]. RPLP1 plays an important role in the elongation step of protein synthesis [11]. The C-terminal 
end of RPLP1 is nearly identical to the C-terminal end of the ribosomal phosphoproteins $\mathrm{P} 0$ and $\mathrm{P} 2$, which can interact with P0 and P2 to form a pentameric complex consisting of P1 and P2 dimers and a P0 monomer [12, 13]. During central nervous system development, RPLP1 promotes embryonic fibroblast senescence-associated proliferation [14]. During flavivirus infection, RPLP1 and RPLP2 are important factors for virus translation and may represent a regulatory step for the translation of specific cellular mRNAs [15]. An increasing number of studies show RPLP1 plays essential roles in cancer development [16]. In colon cancer, RPLP1 expression was fivefold up-regulated in cancerous versus normal tissues [12]. RPLP1 expression is also elevated in gynecologic tumors, including endometrial and ovarian cancers [17]. However, the expression patterns of RPLP1 in breast cancer tissues, especially in TNBC, have not been thoroughly explored.

In our previous pre-experiment, we compared the proteome extracted from TNBC cancers with and without metastasis and found that RPLP1 was 1.6-fold more abundant in metastatic TNBC cancer versus non-metastatic cancer. In the current study, we further explored the role of RPLP1 in TNBC metastasis and determined that RPLP1 may be a novel prognostic marker for TNBC.

\section{Materials and methods}

\section{Patients and tissue samples}

TNBC tissues and adjacent non-tumorous tissues were obtained from 81 TNBC patients who underwent curative resection between 2006 and 2014 at the Affiliated Hospital of Nantong University. All cases were newly diagnosed female patients, who had not yet undergone surgery, radiotherapy, chemotherapy, or biological therapy. Survival data were acquired by periodic interviews with their relatives. Tissue samples were processed immediately following the surgical resection. For histological examination, all tumors and adjacent non-tumor tissues were fixed in formalin and embedded in paraffin blocks. Histological slides stained with hematoxylin and eosin were examined by three pathologists. All studies were approved by the Ethics Committee of Affiliated Hospital of Nantong University.

\section{Immunohistochemistry}

TNBC sections were deparaffinized and rehydrated with graded ethanol, soaked in EDTA (1 mmol/L, $\mathrm{pH} 8.0)$, and then heated to $121^{\circ} \mathrm{C}$ in an autoclave for three min to retrieve the antigen. After natural cooling and rinsing with phosphate-buffered saline (PBS, $\mathrm{pH}$ 7.2), 0.3\% hydrogen peroxide was applied for 20 min to block endogenous peroxide activity. Thereafter, $10 \%$ goat serum was applied for $1 \mathrm{~h}$ at room temperature to block any nonspecific reactions. After washing with PBS ( $\mathrm{pH}$ 7.2), the sections were incubated with a rabbit anti-RPLP1 polyclonal antibody (diluted 1:100; Abcam, ab121190, USA) for $2 \mathrm{~h}$. Negative control slides were processed in parallel using a nonspecific IgG antibody (diluted 1:100; Abcam, USA) at the same concentration as the primary antibody. All sections were processed using the peroxidase-anti-peroxidase kit according to the manufacturer's instructions (Dako, Germany).

\section{Immunohistochemical evaluation}

All the immunostained slides were evaluated by three pathologists who were blinded to sample identity. To assess RPLP1 expression, at least five high-power fields $(400 \times)$ were chosen for each specimen. More than 500 cells were counted to determine the mean percentage of positively stained cells. Staining results were scored semiquantitatively. As previous reported [18], the percentage of positive cells was scored as follows: $0(<10 \%), 1(10$ $30 \%), 2(30-50 \%)$, and $3(50-70 \%)$. The staining intensity was scored as follows: 0 (negative), 1 (moderate), 2 (positive), or 3 (strongly positive). The immunostaining score, which value ranged from 0 to 9 , was calculated as the level of RPLP1 expression. For statistical analysis, $0-4$ is defined as low expression, while $5-9$ is defined as high expression.

\section{Western blotting}

Cells were promptly homogenized in lysis buffer and then centrifuged at $13,000 \mathrm{~g}$ for $20 \mathrm{~min}$ at $4{ }^{\circ} \mathrm{C}$. The supernatant was diluted twofold in SDS loading buffer and denatured at $100{ }^{\circ} \mathrm{C}$ for $15 \mathrm{~min}$. An equivalent amount of protein from each sample was loaded onto a 10\% SDS-PAGE gel and then transferred to a PVDF membrane (Millipore, USA). The membranes were incubated overnight at $4{ }^{\circ} \mathrm{C}$ with the primary antibodies. The antibodies were as follows: anti-RPLP1 (1:500, ab121190, Abcam, Cambridge, MA, USA), anti-E-cadherin antibody (1:1000, ab1416, Abcam), anti-vimentin antibody (1:1000, ab92547, Abcam), anti$\mathrm{N}$-cadherin antibody (1:1000, ab18203, Abcam), anti-Snail antibody (1:1000, ab180714), and anti- $\beta$-actin (1:5000; Abcam). After washing three times with tris-buffered saline with $0.1 \%$ tween- 20 (TBST) for 5 min each time, the membranes were then incubated with horseradish peroxidaseconjugated secondary human anti-mouse or anti-rabbit antibodies (1:2000; Abcam) for $2 \mathrm{~h}$ at room temperature. The bands were then detected using an enhanced chemiluminescence detection system (Bio-Rad, USA).

\section{Real-time quantitative PCR}

The mRNA expression levels of RPLP1 in tissues were assessed by the Real-time quantitative PCR method. The total RNA of tissues was extracted using TRIzol ${ }^{\circledR}$ reagent 
(Thermo Fisher Scientific, Carlsbad, CA) according to the manufacturers' instructions. cDNA for mRNA was synthesized using a Omniscript Reverse Transcription kit (Qiagen, Valencia, CA). For detecting the mRNA level of RPLP1, qPCR was conducted on the Mastercycler Ep Realplex (Eppendorf 2S, Hamburg, Germany). $\beta$-actin was used as an internal control. The relative mRNA expression levels were evaluated by the $2^{-\Delta \Delta C t}$ method [19]. The primer sequences were as follows: For RPLP1: forward, 5'-TGGCCTGGCTTGTTTGC-3', reverse: 5'-CTCGGATTCTTCTTTCTTTGCTT-3'; For $\beta$-actin: forward, $5^{\prime}$-GCGTGACATTAAGGAGAAG- $3^{\prime}$, reverse: 5'-GAAGGAAGGCTGGAAGAG-3'.

\section{Cell cultures}

TNBC cell lines MDA-MB-231, MDA-MB-436, MDAMB-468, MDA-MB-453, and the normal breast epithelial cell line MCF-10A were obtained from the Cell Bank of the Chinese Academy of Sciences (Shanghai, China). These TNBC cells were cultured in Leibovitz's L-15 Medium (L15 medium, Gibco, USA) supplemented with $10 \%$ fetal bovine serum (FBS, Gibco, USA) in an incubator at $37{ }^{\circ} \mathrm{C}$ without $\mathrm{CO}_{2}$. The MCF-10A cells were cultured in MEGM medium (Lonza/Clonetics, USA) in an incubator at $37{ }^{\circ} \mathrm{C}$ with $5 \% \mathrm{CO}_{2}$. All the cells were passaged every 3-5 days. At the time of cell culture, we have tested for Mycoplasma infection, and there is no mycoplasma infection in each culture.

\section{RPLP1 knockdown or overexpression vector construction and transfection}

The human RPLP1 shRNA vector, which targets sequence 5'-CATTAAAGCAGCCGGTGTAAATGTTGAGC-3', was subcloned into the PLKO.1 vector (Invitrogen), and the RPLP1 expression vector, which contains the RPLP1 cDNA sequence, was subcloned into the PLKI.1 vector (Invitrogen). For vector transfection, the cells were seeded the day before transfection using antibiotic-free L15 medium with $10 \%$ FBS. Transient transfection of the shRNA vectors or overexpression vector was carried out using Lipofectamine 2000 in OptiMEM media, as suggested by the manufacturer (Thermo-Fisher). Cells were incubated with the vectors and lipofectamine reagent complexes for $4 \mathrm{~h}$ at $37^{\circ} \mathrm{C}$. FBS was then added to the cells to achieve a final concentration of $10 \%$ in medium. Two days after transfection, puromycin (Sigma-Aldrich, USA) was added to the media at $1 \mu \mathrm{g} / \mathrm{mL}$ for 1 week of selection. The expression levels of the target genes were determined by Western blot analysis.

\section{Cell proliferation assay}

The cell proliferation assay was performed with the Brdu assay kit according to the manufacturer's protocol
(Roche, Germany). Generally, cells were incubated with $100 \mu \mathrm{M}$ Brdu labeling solution for $4 \mathrm{~h}$ at $37^{\circ} \mathrm{C}$. After removing the culture media, the cells were fixed, and the DNA was denatured with FixDenat solution. The antiBrdu-POD working solution and substrate solution were then added, and the absorbances of the samples were measured by an ELISA plate reader at $370 \mathrm{~nm}$.

\section{Colony formation assay}

Cells were seeded in a 6-well plate at a density $\left(1 \times 10^{3}\right.$ cells/well). After cultured for 10 days, cells were fixed with $4 \%$ paraformaldehyde and then counted after staining with crystal violet. Three independent experiments were performed.

\section{Cell invasion assay}

For the invasion assay, cells were suspended in $500 \mu \mathrm{L}$ serum-free media and placed in the upper compartment of the invasion chamber coated with Matrigel (BD Biosciences). The lower compartment was imbued with a complete medium as the chemoattractant. The experiment was performed in triplicate.

\section{Cell migration assay}

A $500 \mu \mathrm{L}$ cell suspension was placed in each insert chamber containing medium free of FBS, while the medium in the lower chamber contained 10\% FBS. The cells that had migrated and attached to the lower surface of the insert were fixed with $4 \%$ formaldehyde and stained with crystal violet. After washing with PBS, the number of cells was counted randomly in five scopes under a microscope $(400 \times)$.

\section{In vivo mouse model}

In this study, all animal experiments were approved by the Animal Ethics committee. Nude mice from each group $(n=6)$ received a tail vein injection of $1 \times 10^{5}$ cells per week for three consecutive weeks [20], and the number of cells injected into each tail vein each time was $1 \times 10^{5}$. The presence of lung metastases was determined by hematoxylin and eosin (H\&E) staining after 10 weeks.

\section{Statistical analysis}

All statistical analyses were carried out using SPSS 20.0 (Statistical Product and Service Solutions, USA). The association between RPLP1 expression and clinicopathological features was computed using the Chi square $\left(\chi^{2}\right)$ test. RPLP1 in TNBC cells was studied using the Spearman rank correlation test, because the data were not normally distributed. For survival analysis, the log rank test and Kaplan-Meier method were used. Multivariate analysis was performed with the Cox's proportional hazards 
model. For all cases, $\mathrm{P}<0.05$ was considered statistically significant.

\section{Results}

The expression of RPLP1 in TNBC tumors, adjacent normal tissue, and cell lines

To confirm the results of our prior proteomics data, we used immunohistochemistry staining to profile the expression of RPLP1 in paraffin embedded TNBC tissues. Representative examples of reactivity for RPLP1 are shown in Fig. 1. RPLP1 expression in TNBC was scored as positive when cytoplasmic staining was strong. We demonstrated that RPLP1 expression is low in the adjacent normal tissues, while it is high in TNBC tissues. Furthermore, the expression of RPLP1 was elevated in the metastasis group compared to the metastasis negative group (Fig. 1). To confirm these immunohistochemical results, we analysed RPLP1 protein expression (via Western blotting) in TNBC and normal breast epithelial cell lines. RPLP1 protein expression was significantly higher in TNBC cells than in normal breast cells, and in MDA-MB-231 cells, the expression of RPLP1 was relatively high (Fig. 2a). Furthermore, we used quantitative PCR to verify the same expression pattern of RPLP1 in the mRNA level (Fig. 2b). These data indicate that RPLP1 expression is correlated with and may be involved in the development of TNBC.

\section{Correlation of RPLP1 expression} with the clinicopathological parameters of TNBC

To examine the relationship between RPLP1 protein expression and common parameters associated with tumor behavior, we compared RPLP1 levels with the clinicopathological features. For statistical analysis, TNBC patients (or tumor tissue specimens) were divided into high and low RPLP1 expression groups, depending on immunostaining score. Statistical analysis indicated that RPLP1 expression was significantly associated with histologic grade $(\mathrm{P}=0.026)$, axillary lymph node status $(\mathrm{P}=0.012)$, and distant metastasis $(\mathrm{P}=0.001)$, but there was no correlation between RPLP1 expression and other factors, such as age and tumor size (Table 1).

\section{Prognostic significance of RPLP1 expression}

Since we found that RPLP1 was associated with histologic grades, we further investigated the role of RPLP1 in breast cancer prognosis. We ultimatelydetermined that high levels of RPLP1, histologic grade, axillary lymph node status, and distant metastasis were significantly associated with patient survival states $(\mathrm{P}=0.014$, $\mathrm{P}=0.021, \mathrm{P}=0.011, \mathrm{P}=0.034$ ) (Table 2). Furthermore, using the Cox's proportional hazards regression model, we determined that RPLP1 expression $(\mathrm{P}=0.001)$, histologic grade $(\mathrm{P}=0.002)$, axillary lymph node status $(\mathrm{P}=0.001)$, and distant metastasis $(\mathrm{P}=0.004)$ were independent prognostic factors in patients with TNBC (Table 3). In univariate analysis, using Kaplan-Meier survival curves, we also found that high RPLP1 expression was statistically correlated with poor overall survival (Fig. 3).

\section{RPLP1 promotes cell invasion and migration in TNBC}

Due to the links between RPLP1 expression and patient characteristics, we went on to investigate the role of RPLP1 in TNBC cell proliferation and invasion. When MDA-MB-231 cells were transfected with the shRNA and expression vector, we confirmed that the shRNA vector effectively knocked down RPLP1 expression, while the expression vector increased RPLP1 expression in TNBC cells (Fig. 4a). When we monitored the proliferation of these cells after $72 \mathrm{~h}$ of transfection, we found that changes in RPLP1 expression did not affect cell growth

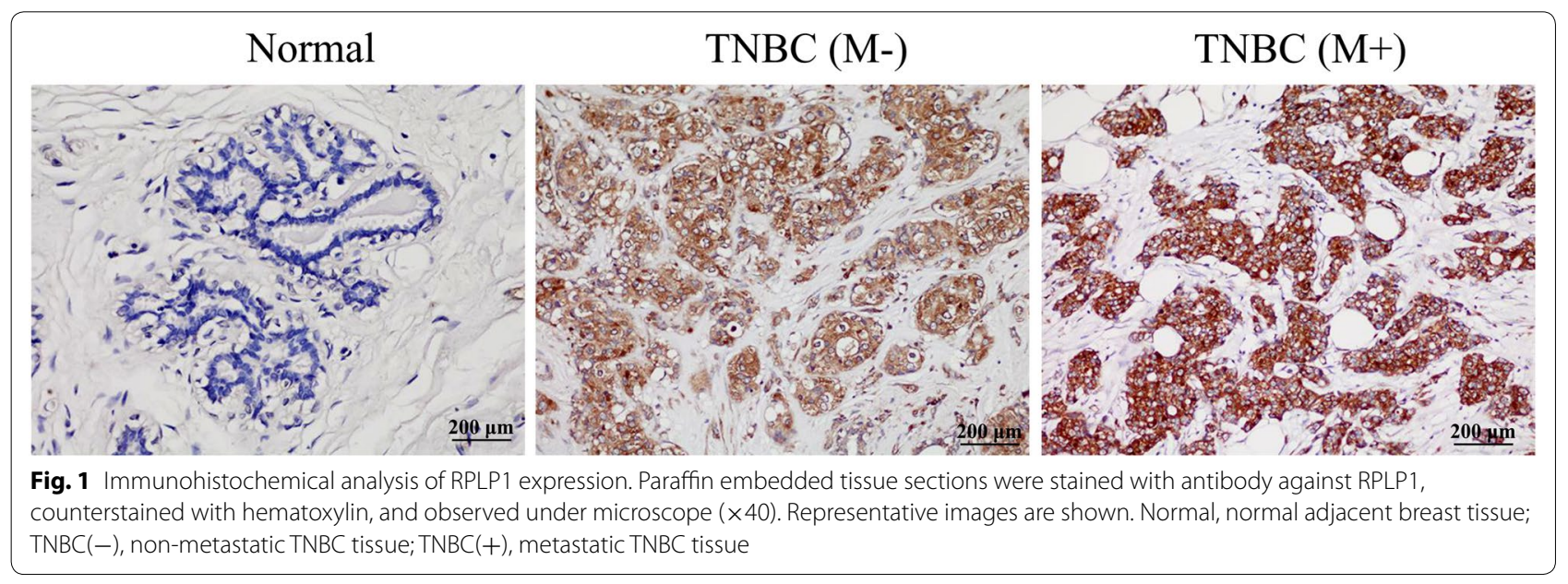


a

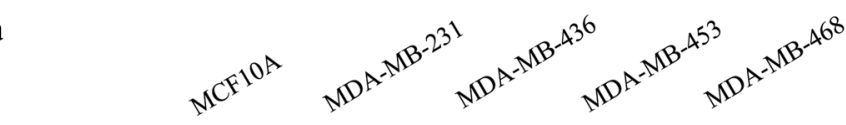

RPLP1
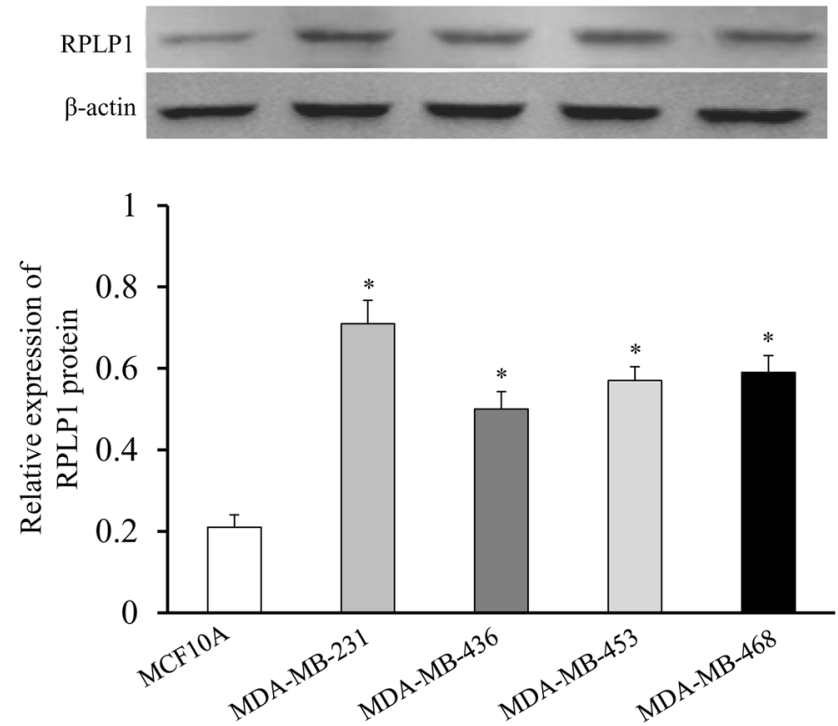

$\mathbf{b}$

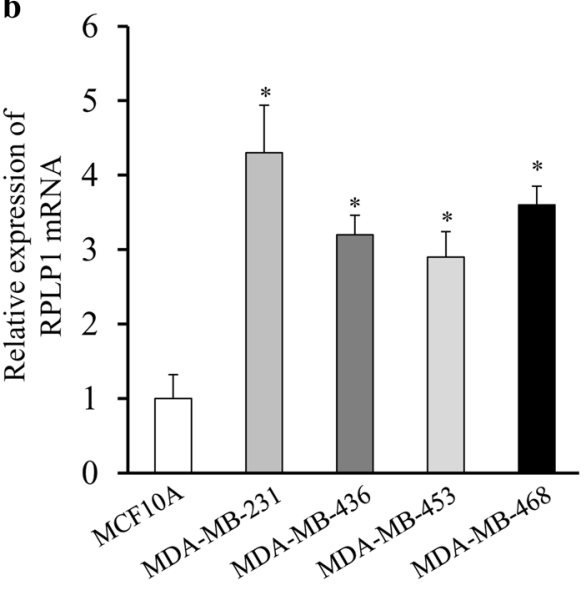

Fig. 2 RPLP1 expression in TNBC and normal breast cells. a RPLP1 protein expression was higher in TNBC cells than in the normal breast cell line. The bar chart demonstrates the ratio of RPLP1 protein to $\beta$-actin using quantitative analysis. b RPLP1 mRNA expression was also higher in TNBC cells than in the normal breast cell line. Data are mean $\pm S D$ for three independent experiments. ${ }^{*} P<0.05$, compared to the MCF-10A cell line

Table 1 Correlation between RPLP1 expression and the clinicopathologic features of TNBC

\begin{tabular}{|c|c|c|c|c|c|}
\hline \multirow[t]{2}{*}{ Clinicopathologic variables } & \multirow[t]{2}{*}{ Cases } & \multicolumn{2}{|c|}{ RPLP1 level } & \multirow[t]{2}{*}{ P value } & \multirow[t]{2}{*}{$x^{2}$} \\
\hline & & Low & High & & \\
\hline Age & 81 & 46 & 25 & 0.263 & 1.639 \\
\hline$\leq 50$ & 39 & 25 & 14 & & \\
\hline$>50$ & 42 & 21 & 21 & & \\
\hline Tumor size $(\mathrm{cm})$ & 81 & 46 & 35 & 0.131 & 4.058 \\
\hline$<2$ & 35 & 23 & 12 & & \\
\hline $2-5$ & 41 & 22 & 19 & & \\
\hline$>5$ & 5 & 1 & 4 & & \\
\hline Grade & 81 & 46 & 35 & 0.026 & 7.308 \\
\hline 1 & 22 & 13 & 9 & & \\
\hline$\|$ & 32 & 23 & 9 & & \\
\hline III & 27 & 10 & 17 & & \\
\hline Axillary lymph node status & 81 & 46 & 35 & 0.012 & 6.868 \\
\hline NO & 48 & 33 & 15 & & \\
\hline $\mathrm{Nx}$ & 33 & 13 & 20 & & \\
\hline Distant metastasis & 81 & 46 & 35 & 0.001 & 12.566 \\
\hline Negative & 60 & 41 & 19 & & \\
\hline Positive & 21 & 5 & 16 & & \\
\hline
\end{tabular}

Statistical analyses were performed by the Pearson $x^{2}$ test * $\mathrm{P}<0.05$ is considered significant
Table 2 Survival status and clinicopathological parameters in TNBC specimens

\begin{tabular}{|c|c|c|c|c|c|}
\hline \multirow[t]{2}{*}{ Criteria } & \multirow[t]{2}{*}{ No. case } & \multicolumn{2}{|c|}{ Survival status } & \multirow[t]{2}{*}{$P$ value } & \multirow[t]{2}{*}{$x^{2}$} \\
\hline & & Alive & Dead & & \\
\hline \multicolumn{6}{|l|}{ Age } \\
\hline$<50$ & 39 & 34 & 5 & 0.105 & 3.025 \\
\hline$\geq 50$ & 42 & 30 & 12 & & \\
\hline \multicolumn{6}{|l|}{ Tumor size } \\
\hline$\leq 2$ & 35 & 27 & 8 & 0.059 & 5.661 \\
\hline $2-5$ & 41 & 35 & 6 & & \\
\hline$>5$ & 5 & 2 & 3 & & \\
\hline \multicolumn{6}{|l|}{ Grade } \\
\hline 1 & 22 & 14 & 8 & $0.021^{*}$ & 7.725 \\
\hline$\|$ & 32 & 30 & 2 & & \\
\hline III & 27 & 20 & 7 & & \\
\hline \multicolumn{6}{|c|}{ Axillary lymph node status } \\
\hline NO & 48 & 43 & 5 & $0.011^{*}$ & 7.939 \\
\hline $\mathrm{Nx}$ & 33 & 21 & 12 & & \\
\hline \multicolumn{6}{|c|}{ Distant metastasis } \\
\hline Negative & 60 & 51 & 9 & $0.034^{*}$ & 5.003 \\
\hline Positive & 21 & 13 & 8 & & \\
\hline \multicolumn{6}{|l|}{ RPLP1 } \\
\hline Low & 46 & 41 & 5 & $0.014^{*}$ & 6.572 \\
\hline High & 35 & 23 & 12 & & \\
\hline
\end{tabular}

Statistical analyses were performed by the Pearson $x^{2}$ test

* $\mathrm{P}<0.05$ is considered significant 
Table 3 Contribution of various potential prognostic factors to survival

\begin{tabular}{llll}
\hline & Hazard ratio & $\begin{array}{l}\mathbf{9 5 \%} \\
\text { confidence } \\
\text { interval }\end{array}$ & P \\
\hline Age & 1.150 & $0.696-1.902$ & 0.586 \\
Tumor size & 1.472 & $0.887-2.443$ & 0.135 \\
Grade & 1.890 & $1.267-2.819$ & $0.002^{*}$ \\
Axillary lymph node status & 2.541 & $1.445-4.467$ & $0.001^{*}$ \\
Distant metastasis & 2.526 & $1.337-4.770$ & $0.004^{*}$ \\
RPLP1 & 2.552 & $1.499-4.344$ & $0.001^{*}$ \\
\hline
\end{tabular}

Statistical analyses were performed by the Pearson $x^{2}$ test

* $\mathrm{P}<0.05$ is considered significant

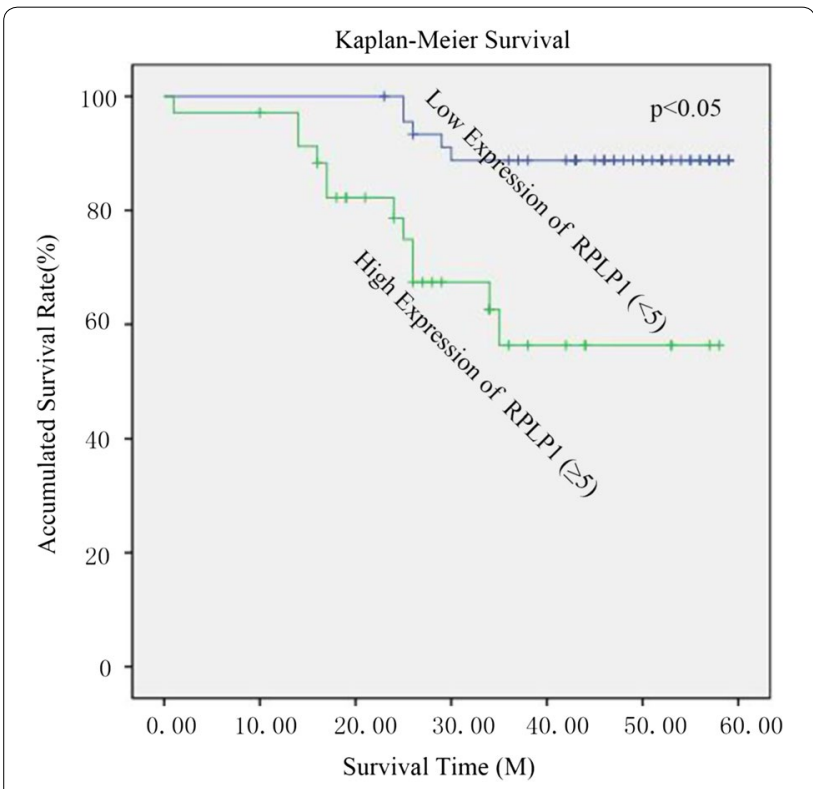

Fig. 3 Kaplan-Meier survival curves for high versus low RPLP1 expression in 81 patients with TNBC. Patients in the high expression group had significantly shorter overall survival than those in the low expression group

(Fig. 4b). In addition, the clone formation assay has been carried out and we found that changes in RPLP1 expression did not affect cell clone formation abilities (Fig. 4c). We also observe that inhibition of RPLP1 expression can significantly inhibit cell invasion, and overexpression of RPLP1 increased cell invasion in the MDA-MB-231 and
MDA-MB-468 cell line (Fig. 4d). Lastly, the migration potential of cells upon overexpression and knockdown of RPLP1 has been evaluated. We also observed that inhibition of RPLP1 expression can significantly inhibit cell migration, and overexpression of RPLP1 enhanced cell migration in the MDA-MB-231 and MDA-MB-468 cell line (Fig. 5). These data indicate that RPLP1 promotes cancer metastasis in TNBC, but it may not be absolutely required for cell growth or proliferation.

\section{The mechanism that RPLP1 affects metastasis may be through EMT}

The epithelial-mesenchymal transition plays an essential role in TNBC metastasis. To investigate the mechanism of RPLP1 in TNBC metastasis, we examined the effect of RPLP1 on the epithelial-mesenchymal transition in MDA-MB-231 cells. When we knocked down RPLP1 expression, the epithelial cell marker E-cadherin was increased, and the mesenchymal cell marker N-cadherin was decreased. However, overexpression promoted expression of the mesenchymal cell marker $\mathrm{N}$-cadherin and decreased expression of epithelial cell marker E-cadherin (Fig. 6a). These data indicate RPLP1 mediates cell invasion and affects the cell epithelial-mesenchymal transition. Histologic analysis confirmed that MDA-MB-231 overexpressed RPLP1 cells had an increased ability to metastasize to the lungs compared to the MDA-MB-231 control. Contrary, inhibition of RPLP1 expression can significantly inhibit metastasis (Fig. 6b).

\section{Discussion}

Triple negative breast cancer bears the worst prognosis of any breast cancer, because it is resistant to most conventional therapies [21]. Metastasis is the main cause of patient death in women with TNBC. Here, we show RPLP1 expression is elevated in the TNBC, especially in metastatic tissues when compared with normal tissues, implicating RPLP1 may be involved in the development and metastasis of TNBC. In addition, we showed that RPLP1 promotes the cell epithelial-mesenchymal transition and may play a direct role in influencing cancer spread.

Other research studies have reported that RPLP1 is associated with the progression of colon cancer and gynecologic tumors [21]. In colon cancer, RPLP1 gene expression is significantly enhanced [21]. In 140 biopsies

\footnotetext{
(See figure on next page.)

Fig. 4 The effect of RPLP1 expression on cell behavior. a MDA-MB-231 cells were transfected with the control vector, RPLP1 shRNA vector, or RPLP1 expression vector. The expression of RPLP1 was detected by Western blot. $\mathbf{b}$ Brdu assays showing cell proliferation in respect to RPLP1 expression. c The clone formation assay shows that changes in RPLP1 expression did not affect cell clone formation abilities. $\mathbf{d}$ Matrigel transwell assay shows cell invasion when RPLP1 is overexpressed or RPLP1 expression is suppressed in MDA-MB-231 and MDA-MB-468 cells. Representative images are shown. ${ }^{*} \# \mathrm{P}<0.05$ compared to control vector
} 

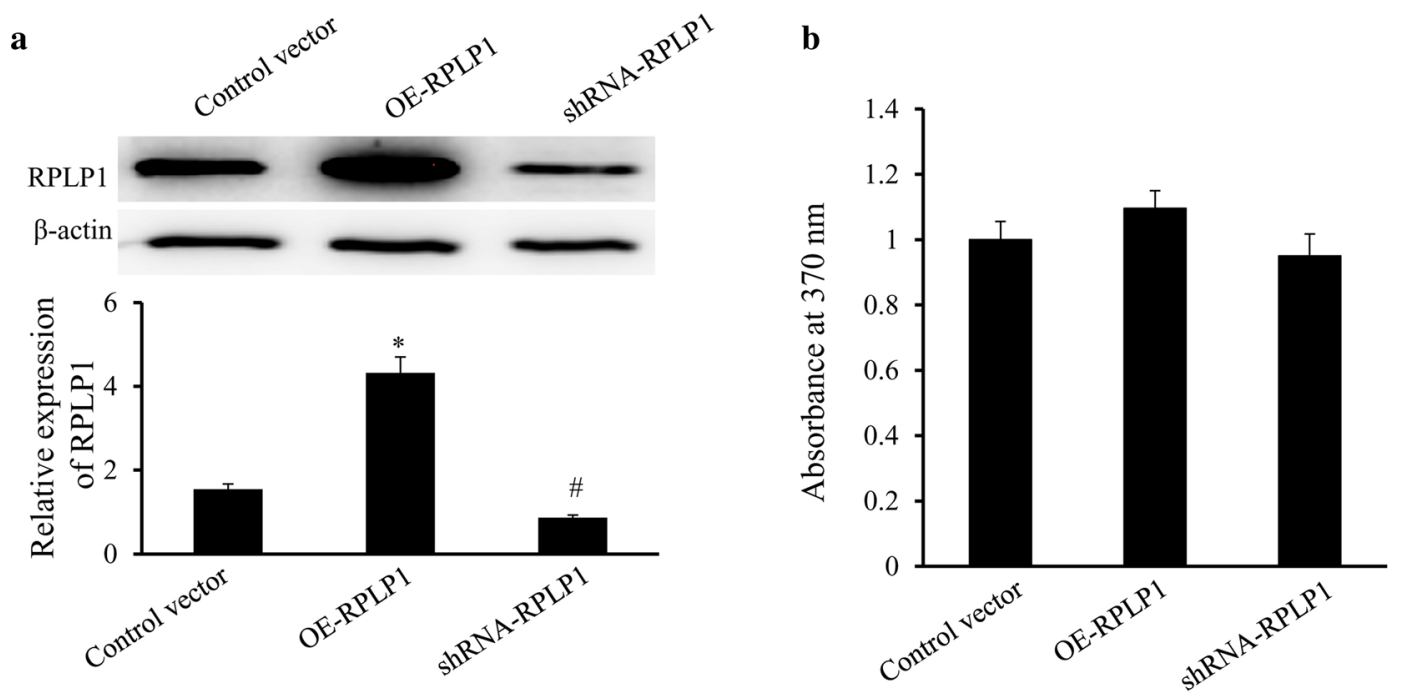

c

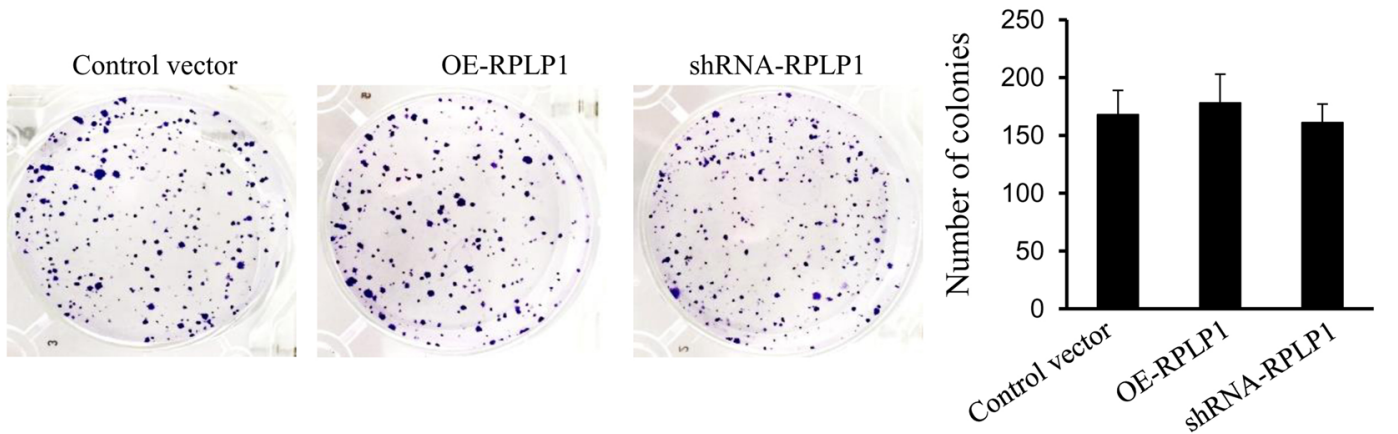

d

Control vector

OE-RPLP1

shRNA-RPLP1

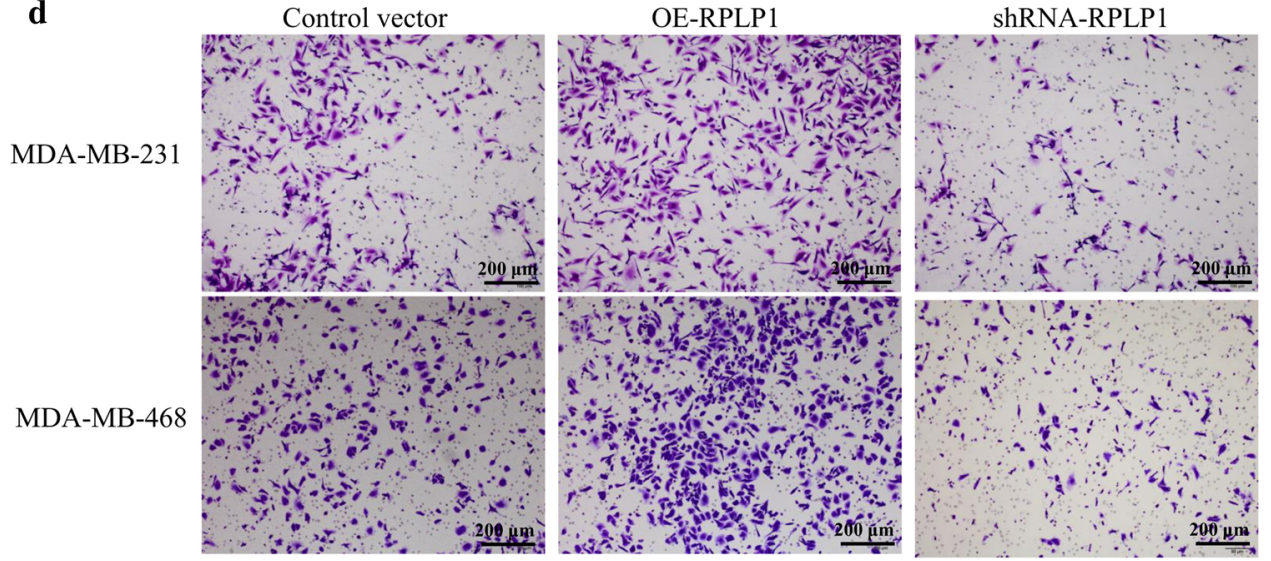

MDA-MB-231
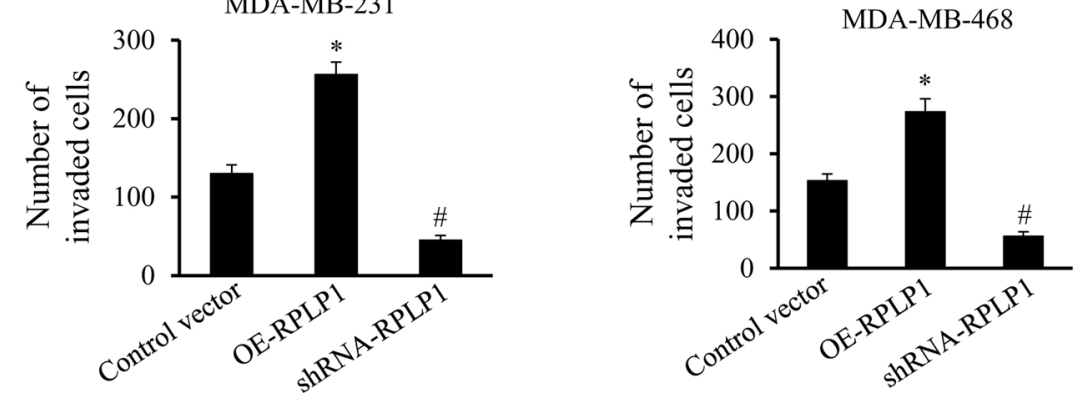


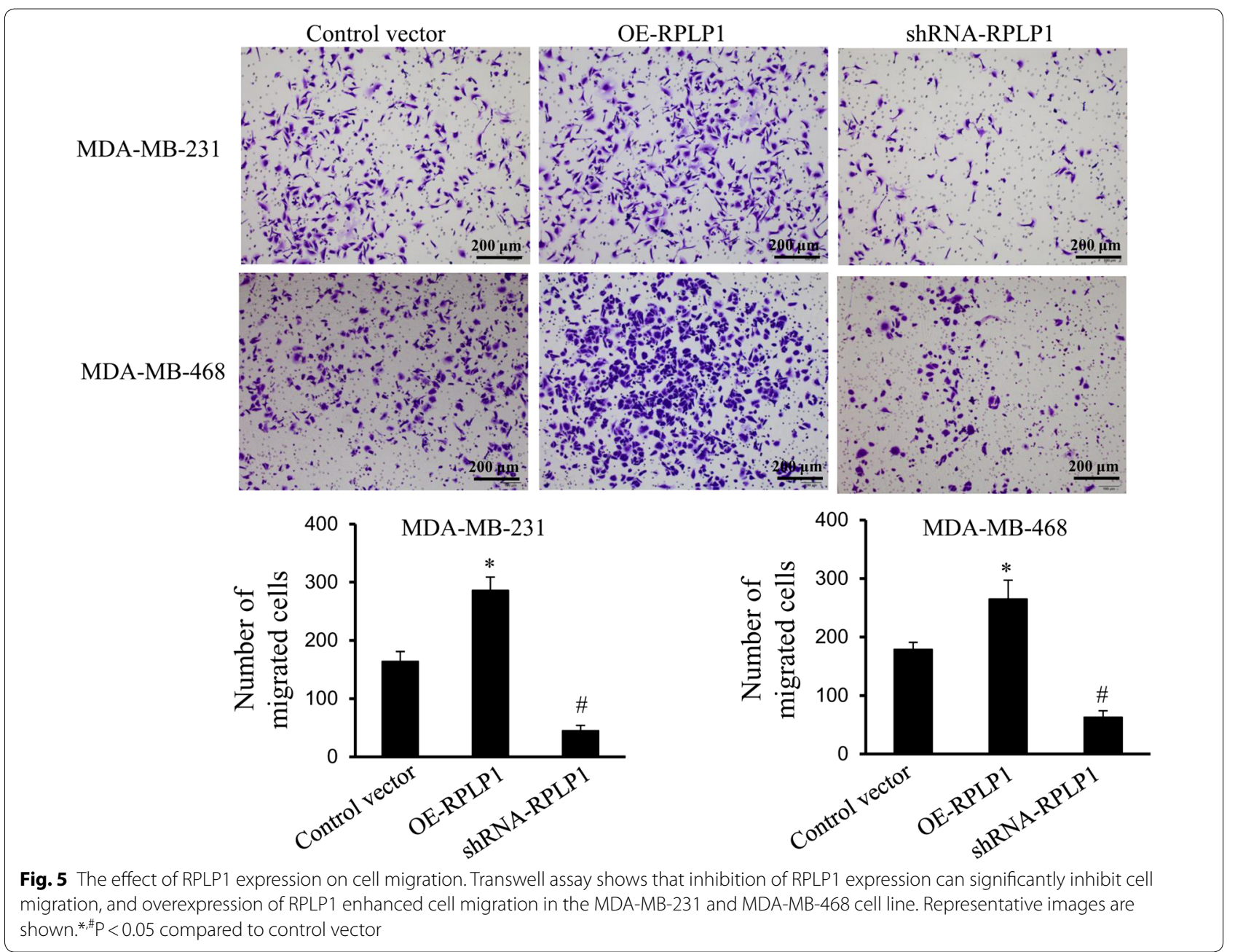

of gynecologic cancers (46 endometrioid and 94 ovarian), RPLP1 was up-regulated in $27 \%$ of the tumors [17]. As breast cancer represents another important feminine cancer, that is associated with hormone changes, we elected to investigate the role of RPLP1 in breast tumors [22]. TNBC is an especially devastating form of breast cancer that lacks expression of ER, PR, and Her-2 and therefore is generally resistant to common anti-hormone and anti-Her-2 therapies. Here, we show that RPLP1 expression is associated with TNBC and its clinicopathological features, such as axillary lymph node status, vein invasion, and metastasis. Ultimately, elevated RPLP1 expression (at both the RNA and protein level) was associated with a poor prognosis of TNBC.

When we examined the relationship between RPLP1 and tumor characteristics, we determined that high RPLP1 expression promotes cell invasion. However, knocking down RPLP1 expression did not affect cell proliferation, indicating that RPLP1 largely affects motility mechanisms and metastasis, rather than tumor growth. Increasing numbers of studies have shown that the epithelial-mesenchymal transition is a key mechanism involved in cancer metastasis $[17,23]$. In conjunction with these findings, we determined that RPLP1 expression promoted the epithelial-mesenchymal transition in TNBC metastasis.

\section{Conclusions}

This study indicated a link between RPLP1 overexpression and histologic grade, axillary lymph node status and distant metastasis in TNBC patients, which reveals RPLP1 may have significant value as a prognostic indicator for TNBC patients. Our results also indicated that 


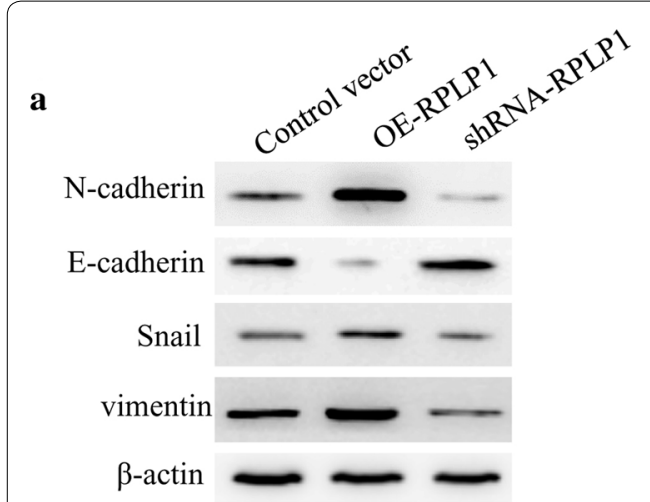

a

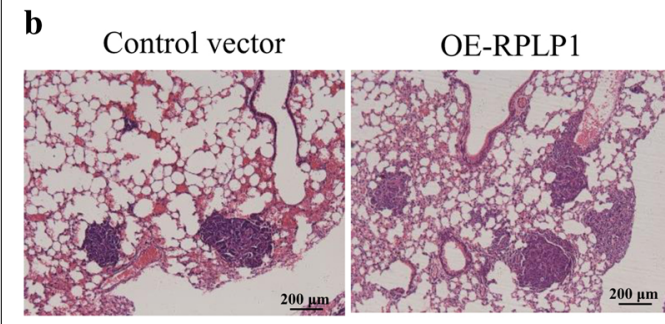

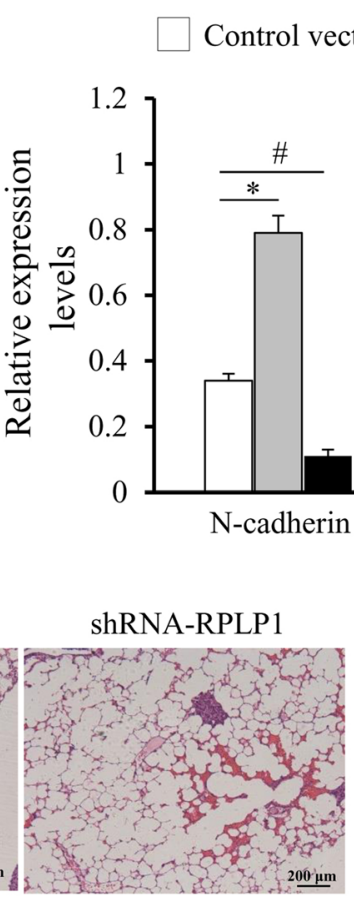
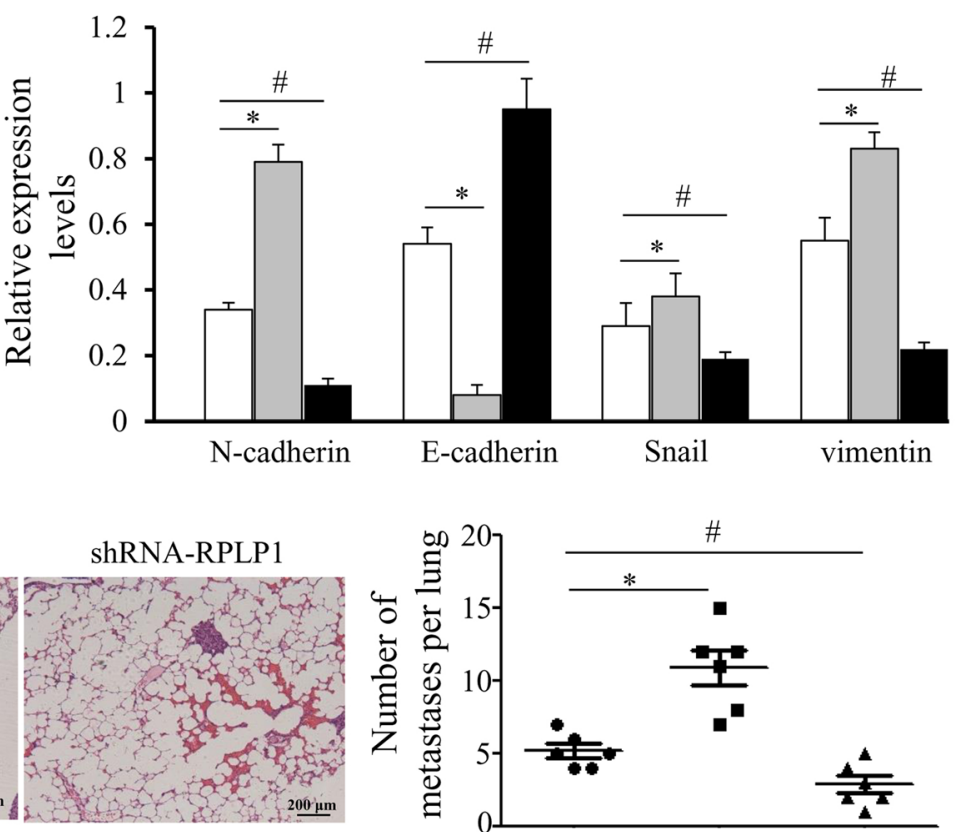

Control OE-RPLP1 shRNA-RPLP1

Fig. 6 The effect of RPLP1 expression on the epithelial-mesenchymal transition. MDA-MB-231 cells were transfected with the control vector, RPLP1 shRNA vector, or RPLP1 expression vector. a Western blots showing the changes N-cadherin and E-cadherin expression. b MDA-MB-231 cells transfected with OE-RPLP1 are more metastatic than MDA-MB-231 cells transfected control vector, and cells transfected with shRNA-RPLP1 are less metastatic than MDA-MB-231 cells transfected control vector in vivo, as indicated by HE staining. Representative images are shown. ${ }^{*}, \# P<0.05$ compared to control vector

RPLP1 may be a novel target to prevent or reduce breast cancer metastasis and could be the basis for future anticancer therapies, especially for difficult to treat TNBC.

\section{Authors' contributions}

Conceived and designed the experiments: ZXH, QX ZMS. Performed the experiments: ZXH, QX, JW, YYQ. Analyzed and interpreted the data: ZXH, XMM. Wrote the paper: ZXH, WWS, ZMS. Collected tissue samples: QX, XW, YHC, YYQ WWS. Decided to submit the article for publication: ZXH, QX, XW, JW, XMM, YHC, YYQ, WWS, ZMS. All authors read and approved the final manuscript.

\section{Author details}

1 Department of Breast Surgery, Shanghai Cancer Center, Fudan University, Shanghai 200032, People's Republic of China. ${ }^{2}$ Department of General Surgery, Affiliated Hospital of Nantong University, Nantong 226001, Jiangsu, People's Republic of China. ${ }^{3}$ Department of General Surgery, The Fourth Affiliated Hospital of Nantong University, Yancheng 224000, Jiangsu, People's Republic of China.

\section{Acknowledgements}

We appreciated that Dr. Feiran Wang provided the technique support during the immunohistochemistry.

\section{Competing interests}

The authors declare that they have no competing interests.
Availability of data and materials

All the data and material could be traced from the paper we have published before.

\section{Consent for publication}

All the listed authors have participated actively in the study, and have seen and approved the submitted manuscript.

\section{Ethics approval and consent to participate}

All patients selected for our study were fully informed about our experimental protocols, which were approved by Ethics Committee of Affiliated Hospital of Nantong University, and provided written informed consent from each patient.

\section{Funding}

This study was supported by the National Natural Science Foundation of China (No. 81672596) and the Social Development Foundation of Nantong City (MS12017007-1).

\section{Publisher's Note}

Springer Nature remains neutral with regard to jurisdictional claims in published maps and institutional affiliations.

Received: 25 July 2018 Accepted: 8 October 2018

Published online: 25 October 2018 


\section{References}

1. Liu X, Qu JK, Zhang J, Yan Y, Zhao XX, Wang JZ, Qu HY, Liu L, Wang JS, Duan $X Y$. Prognostic role of pretreatment neutrophil to lymphocyte ratio in breast cancer patients: a meta-analysis. Medicine. 2017;96(45):e8101.

2. Siegel RL, Miller KD, Jemal A. Cancer statistics, 2018. CA Cancer J Clin. 2018;68(1):7-30.

3. Smith RA, Andrews KS, Brooks D, Fedewa SA, Manassaram-Baptiste D, Saslow D, Brawley OW, Wender RC. Cancer screening in the United States, 2018: a review of current American Cancer Society guidelines and current issues in cancer screening. CA Cancer J Clin. 2018;68(4):297-316.

4. Carey L, Winer E, Viale G, Cameron D, Gianni L. Triple-negative breast cancer: disease entity or title of convenience? Nat Rev Clin Oncol. 2010;7(12):683-92.

5. Li J, Lai Y, Ma J, Liu Y, Bi J, Zhang L, Chen L, Yao C, Lv W, Chang G, et al. miR-17-5p suppresses cell proliferation and invasion by targeting ETV1 in triple-negative breast cancer. BMC Cancer. 2017;17(1):745.

6. Dietze EC, Chavez TA, Seewaldt VL. Obesity and triple-negative breast cancer: disparities, controversies, and biology. Am J Pathol. 2018;188(2):280-90.

7. Santoni M, Romagnoli E, Saladino T, Foghini L, Guarino S, Capponi M, Giannini M, Cognigni PD, Ferrara G, Battelli N. Triple negative breast cancer: key role of tumor-associated macrophages in regulating the activity of anti-PD-1/PD-L1 agents. Biochem Biophys Acta. 2018;1869(1):78-84.

8. Nakayama T, Okada N, Yoshikawa M, Asaka D, Kuboki A, Kojima H, Tanaka Y, Haruna SI. Assessment of suitable reference genes for RT-qPCR studies in chronic rhinosinusitis. Sci Rep. 2018;8(1):1568.

9. Ishii K, Washio T, Uechi T, Yoshihama M, Kenmochi N, Tomita M. Characteristics and clustering of human ribosomal protein genes. BMC Genomics. 2006;7:37

10. Doherty L, Sheen MR, Vlachos A, Choesmel V, O'Donohue MF, Clinton C, Schneider HE, Sieff CA, Newburger PE, Ball SE, et al. Ribosomal protein genes RPS10 and RPS26 are commonly mutated in Diamond-Blackfan anemia. Am J Hum Genet. 2010;86(2):222-8.

11. Artero-Castro A, Kondoh H, Fernandez-Marcos PJ, Serrano M, y Cajal SR, Lleonart ME. Rplp1 bypasses replicative senescence and contributes to transformation. Exp Cell Res. 2009;315(8):1372-83.

12. Du YJ, Luo XY, Hao YZ, Zhang T, Hou WR. CDNA cloning and overexpression of acidic ribosomal phosphoprotein P1 gene (RPLP1) from the giant panda. Int J Biol Sci. 2007;3(7):428-33.
13. Davies NJ, Krusche P, Tauber E, Ott S. Analysis of $5^{\prime}$ gene regions reveals extraordinary conservation of novel non-coding sequences in a wide range of animals. BMC Evol Biol. 2015;15:227.

14. Hu C, Huang W, Chen H, Song G, Li P, Shan Q, Zhang X, Zhang F, Zhu H, Wu L, et al. Autoantibody profiling on human proteome microarray for biomarker discovery in cerebrospinal fluid and sera of neuropsychiatric lupus. PLoS ONE. 2015;10(5):e0126643.

15. Campos RK, Wong B, Xie X, Lu YF, Shi PY, Pompon J, Garcia-Blanco MA, Bradrick SS. RPLP1 and RPLP2 are essential flavivirus host factors that promote early viral protein accumulation. J Virol. 2017;91(4):0176.

16. Barnes DJ, Hookway E, Athanasou N, Kashima T, Oppermann U, Hughes S, Swan D, Lueerssen D, Anson J, Hassan AB. A germline mutation of CDKN2A and a novel RPLP1-C19MC fusion detected in a rare melanotic neuroectodermal tumor of infancy: a case report. BMC Cancer. 2016;16:629.

17. Artero-Castro A, Castellvi J, Garcia A, Hernandez J, y Cajal RS, Lleonart ME. Expression of the ribosomal proteins Rplp0, Rplp1, and Rplp2 in gynecologic tumors. Hum Pathol. 2011;42(2):194-203.

18. Richards CE, Vellanki SH, Smith YE, Hopkins AM. Diterpenoid natural compound C4 (Crassin) exerts cytostatic effects on triple-negative breast cancer cells via a pathway involving reactive oxygen species. Cell Oncol. 2018;41(1):35-46.

19. Livak KJ, Schmittgen TD. Analysis of relative gene expression data using real-time quantitative PCR and the $2(-\triangle \triangle C T)$ method. Methods. 2001;25(4):402-8

20. Kuang XY, Jiang HS, Li K, Zheng YZ, Liu YR, Qiao F, Li S, Hu X, Shao ZM. The phosphorylation-specific association of STMN1 with GRP78 promotes breast cancer metastasis. Cancer Lett. 2016:377(1):87-96.

21. Bianchini G, Balko JM, Mayer IA, Sanders ME, Gianni L. Triple-negative breast cancer: challenges and opportunities of a heterogeneous disease. Nat Rev Clin Oncol. 2016;13(11):674-90.

22. Kumar P, Aggarwal R. An overview of triple-negative breast cancer. Arch Gynecol Obstet. 2016:293(2):247-69.

23. Diepenbruck M, Christofori G. Epithelial-mesenchymal transition (EMT) and metastasis: yes, no, maybe? Curr Opin Cell Biol. 2016:43:7-13.
Ready to submit your research? Choose BMC and benefit from:

- fast, convenient online submission

- thorough peer review by experienced researchers in your field

- rapid publication on acceptance

- support for research data, including large and complex data types

- gold Open Access which fosters wider collaboration and increased citations

- maximum visibility for your research: over $100 \mathrm{M}$ website views per year

At $\mathrm{BMC}$, research is always in progress.

Learn more biomedcentral.com/submissions 